\title{
Disposition of Ethanol and Acetaldehyde in Late Pregnant Rats and Their Fetuses
}

\author{
ANTONIO ZORZANO AND EMILIO HERRERA \\ Departamento de Bioquímica y Fisiologia [A.Z.], Facultad de Biologia, Universidad de Barcelona, and \\ Departamento de Bioquímica y Biología Molecular [E.H.], Universidad de Alcalá de Henares y Hospital Ramón \\ y Cajal, Ctra. de Colmenar Km 9, 28034 Madrid, Spain
}

\begin{abstract}
The pattern of ethanol and acetaldehyde appearance in blood after an oral ethanol gavage $(4 \mathrm{~g} / \mathrm{kg}$ body wt) was not different at 12 or 21 days' gestation compared to virgin rats. Five min after maternal ethanol administration, concentrations of ethanol in fetal blood were lower than in maternal blood; however, at $15 \mathrm{~min}$ after ethanol administration, fetal and maternal blood levels were similar. Ethanol concentrations in fetal blood and amniotic fluid were already at equilibrium 5 min after ethanol administration. Acetaldehyde concentrations in fetal blood and in amniotic fluid were undetectable at all the times investigated, with the exception of fetuses from two pregnant rats studied $3 \mathrm{~h}$ after ethanol administration. Alcohol dehydrogenase activity in fetal liver and in placenta at late pregnancy was very low or undetectable, suggesting a very low rate of ethanol oxidation in vivo. After intravenous administration of acetaldehyde $(10 \mathrm{mg} / \mathrm{kg}$ body wt), blood acetaldehyde concentrations were higher in pregnant than in virgin rats. Acetaldehyde concentrations in fetal blood and in amniotic fluid were similar to maternal blood at 2,5 , and $30 \mathrm{~min}$ after injection. When circulating concentrations of maternal and fetal acetaldehyde, obtained after either ethanol or acetaldehyde administration, were plotted, it was found that fetal blood concentrations of acetaldehyde were only detectable when maternal blood concentrations were greater than $80 \mu \mathrm{M}$. Concerning the acetaldehyde oxidation capacity, both the high and low affinity components of aldehyde dehydrogenase activity in fetal liver and placenta were very low as compared with maternal liver. However, aldehyde dehydrogenase activity in fetal liver was much higher than in placenta. It is proposed that ethanol present in the feto/placental unit is metabolized mainly by the maternal liver and that there is a threshold for acetaldehyde above which the capacity for acetaldehyde metabolism is surpassed. (Pediatr Res 25: 102-106, 1989)
\end{abstract}

In rodents, ethanol administration has been found to be teratogenic (1-3). The retarded growth and abnormalities in fetal development observed in the offspring of mothers who had consumed high doses of ethanol during pregnancy has been referred to as the fetal alcohol syndrome (4-7). The teratogenic actions of ethanol might be mediated by ethanol itself, by acetaldehyde, or by another as yet unknown metabolite synthesized as a consequence of ethanol ingestion (8).

Received March 28, 1988; accepted September 15, 1988.

Correspondence Prof. Emilio Herrera, Servicio de Bioquimica, Hospital Ramón y Cajal, Ctra. de Colmenar Km 9, 28034 Madrid, Spain.

Supported by a grant from the CAYCIT of Spain.
Although fetal effects of maternal ingestion of ethanol have been described $(9-11)$, there is little information regarding the pharmacokinetics of ethanol or its toxic metabolite, acetaldehyde, during pregnancy. Ethanol is known to cross the placental barrier freely and to be distributed in fetal tissues (12-14). An exaggerated acetaldehyde response after ethanol administration has been described during pregnancy (15), but it is not certain that acetaldehyde crosses the placenta $(15,16)$. In fact, whereas acetaldehyde administered at high dose to pregnant mice appears to induce teratogenic effects (17), fetal blood acetaldehyde concentrations are always lower than levels in maternal blood, even after high ethanol doses in pregnant rats $(18,19)$. In the present study, we investigated the pattern of ethanol and acetaldehyde metabolism in pregnant rats and the disposition of both metabolites in fetal blood and amniotic fluid. In addition, the activities of alcohol dehydrogenase and aldehyde dehydrogenase in maternal and fetal liver and placenta at different gestational days were examined.

\section{MATERIALS AND METHODS}

Animals. Wistar female rats from our own colony weighing $160 \mathrm{~g}$ were mated, and gestation was timed from the appearance of spermatozoids in vaginal smears. Sex-matched and agematched virgin rats were studied in parallel. Animals were housed in breeding cages in a light- and temperature-controlled room (12 h on-off; $23 \pm 1^{\circ} \mathrm{C}$ ) and fed ad libitum with Purina chow pellets (UAR-Panlab, Barcelona, Spain). Animals were studied in the fed state or $4 \mathrm{~h}$ after the start of the light cycle.

Ethanol and acetaldehyde administration studies. After gastric administration of $4 \mathrm{~g} / \mathrm{kg}$ body weight of ethanol to fed virgin, 12- or 21-day pregnant rats, blood was collected from the tail to determine concentrations of ethanol and acetaldehyde. Blood samples were collected in tubes containing $300 \mu \mathrm{l}$ of $100 \mathrm{mM}$ chloral hydrate. In a different set of experiments and at different time periods, samples of fetal blood and amniotic fluid were collected. Ethanol and acetaldehyde determinations were always conducted with fresh blood samples on the same day as their collection. The method of Von Wartburg and Ris (20) was followed with some modifications $(18,21)$. Immediately after placing blood aliquots in chloral hydrate, proportions were adjusted to $1: 1(\mathrm{vol} / \mathrm{vol})$ by weighing the tubes and adding the appropriate amount of chloral hydrate. After being thoroughly mixed at $4^{\circ} \mathrm{C}$ and centrifuged at $1000 \times \mathrm{g}$ for $15 \mathrm{~min}, 150 \mu \mathrm{l}$ of supernatant aliquots were placed in $1-\mathrm{ml}$ glass vials containing $300 \mu \mathrm{l}$ saline, $500 \mu \mathrm{l}$ of $1.5 \mathrm{mM}$ 1-propanol (internal standard) and $50 \mu \mathrm{l}$ of $60 \% \mathrm{HClO}_{4}$, after which the vials were hermetically sealed. External standard vials, containing plasma from untreated animals supplemented with chloral hydrate and saline and different amounts of ethanol and acetaldehyde, were always run in parallel with blank vials. All vials were subjected to head space gas chromatography performed with a Perkin-Elmer Sigma 
15 apparatus (Perkin-Elmer Corp., Norwalk, CT) and a column of Carbowax 1540 (Perkin-Elmer). Temperatures were $60^{\circ} \mathrm{C}$ for the sample thermostat and $150^{\circ} \mathrm{C}$ for the injector and detector block. With this procedure, the amounts of ethanol and acetaldehyde recovered from fresh plasma samples were 106 and $98 \%$, respectively. A different set of studies was performed after the intravenous (tail vein) injection of $10 \mathrm{mg} / \mathrm{kg}$ body weight of acetaldehyde in virgin and 21-day pregnant rats. After 2,5 , or $30 \mathrm{~min}$, rats were killed, and samples from maternal and fetal blood and amniotic fluid were collected for determination, with the above methodology, of acetaldehyde concentrations. In all experiments, results were expressed as mean $\pm \mathrm{SE}$ and statistical comparison among groups was done by Student's $t$ test.

Determination of alcohol dehydrogenase and aldehyde dehydrogenase activities. In another set of experiments, samples were taken from the livers of virgin and pregnant rats and their fetuses as well as from the placentas. Immediately after excision, tissue samples were placed in ice-cold $50 \mathrm{mM}$ sodium phosphate buffer, pH 7.4, and after homogenization in a glass Potter vessel with Teflon pestle in an ice bath and sonication in an MSE sonifier (set at $12 \mu$, for $1 \mathrm{~min}$ ) they were centrifuged at $56,000 \times \mathrm{g}$ for $20 \mathrm{~min}$ at $4^{\circ} \mathrm{C}$. Supernatants were then centrifuged at $143,000 \times$ $\mathrm{g}$ for $60 \mathrm{~min}$, and final supernatants were immediately used for enzymatic assays. Alcohol and aldehyde dehydrogenase activities were assayed during the same day following the spectrophotometric methods described by Von Wartburg et al. (22) and by Blair and Bodley $(23)$ with a few modifications $(21,24)$.

Alcohol dehydrogenase was assayed at $25^{\circ} \mathrm{C}$ in cuvettes containing either $67 \mathrm{mM}$ sodium phosphate $(\mathrm{pH} 7.4)$ or $100 \mathrm{mM}$ glycine- $\mathrm{NaOH}$ buffers (pH 8.8 or 10.5 ), $1.3 \mathrm{mM} \mathrm{NAD}^{+}$and $0.8-$ $1.0 \mathrm{mg}$ of protein $(20 \mu \mathrm{l}$ of sample) in $3 \mathrm{ml}$. The reaction was initiated by the addition of ethanol to give a final concentration of $17 \mathrm{mM}$ for measurement of total activity. The aldehyde dehydrogenase assay was performed at $37^{\circ} \mathrm{C}$ in cuvettes containing $100 \mathrm{mM}$ glycine- $\mathrm{NaOH}, 130 \mathrm{mM} \mathrm{KCl}, 1 \mathrm{mM}$ pyrazol and 1 $\mathrm{mM} \mathrm{NAD}{ }^{+}, \mathrm{pH} 8.8$, and $0.8-1.0 \mathrm{mg}$ of protein in $1 \mathrm{ml}$. The reaction was started by adding 0.05 or $20 \mathrm{mM}$ acetaldehyde to determine the high and low affinity components of ALDH, respectively. For Km and $\mathrm{V}_{\text {max }}$ measurements of ALDH, acetaldehyde was added at final concentrations of $0.005,0.01,0.02$, $0.04,0.05,0.3,1.0,4.0,20$, and $40 \mathrm{mM}$. In all assays, measurements were made with a Beckman DU-8B (Kinetics II; Beckman Instruments, Inc., Fullerton, CA) spectrophotometer at $340 \mathrm{~nm}$. One unit of enzymatic activity corresponds to $1 \mu \mathrm{mol}$ of substrate transformed $/ \mathrm{min}$. Proteins were determined by the Lowry method (25). Results were expressed as mean $\pm \mathrm{SE}$, and statistical comparison among groups was done with Student's $t$ test.

\section{RESULTS}

Ethanol metabolism in pregnant rats and their fetuses. The pattern of ethanol and acetaldehyde concentrations in blood from virgin and pregnant rats after oral administration of $4 \mathrm{~g} / \mathrm{kg}$ body wt of ethanol was investigated initially. Results are presented in Table 1 . Blood ethanol concentrations showed a progressive increase, peaking at $180 \mathrm{~min}$ after ethanol administration. From 180 to $300 \mathrm{~min}$ thereafter, ethanol concentrations decreased very slowly. Micromolar concentrations of acetaldehyde were present in blood at all times studied. Blood ethanol and acetaldehyde concentrations obtained after ethanol ingestion were not different in 12- or 21-day pregnant rats (Table 1).

In a different set of experiments, ethanol and acetaldehyde concentrations were examined in maternal and fetal blood as well as in amniotic fluid from 21-day pregnant rats after an oral gavage of $4 \mathrm{~g} / \mathrm{kg}$ body wt of ethanol. At different times, mothers and their fetuses were decapitated, and their blood was collected from the neck wound for ethanol determinations. In this experimental model, fetal blood concentrations of ethanol were low compared to maternal blood $5 \mathrm{~min}$ after ethanol administration; however, at that time, ethanol concentrations in fetal blood and amniotic fluid were already in equilibrium (Table 2). After 15 min and up to $300 \mathrm{~min}$ after ethanol administration, fetal blood concentrations of ethanol were similar to maternal blood values.

Acetaldehyde concentrations in blood and amniotic fluid are presented in Table 3. Acetaldehyde concentrations in maternal blood increased somewhat with time after ethanol gavage. Under these conditions, 5 or $15 \mathrm{~min}$ after ethanol administration, fetal blood levels were always undetectable (Table 3 ). It should be pointed out that, $180 \mathrm{~min}$ after ethanol administration, a detectable concentration of acetaldehyde was present in fetal blood from two pregnant rats which showed high acetaldehyde concentrations (close to $100 \mu \mathrm{M}$ ). In the rest of the pregnant rats in the same group (eight others), all of which had lower circulating acetaldehyde concentrations, fetal blood acetaldehyde was always

Table 2. Ethanol concentrations $(m M)$ in maternal and fetal blood and amniotic fluid after maternal administration of $4 \mathrm{~g} /$ $\mathrm{kg}$ body wt of ethanol*

\begin{tabular}{lcccc}
\hline & \multicolumn{4}{c}{ Min after ethanol } \\
\cline { 2 - 5 } & 5 & 15 & 180 & 300 \\
\hline Maternal blood & $34.2 \pm 4.0$ & $27.2 \pm 2.3$ & $27.0 \pm 2.9$ & $26.3 \pm 3.4$ \\
Fetal blood & $9.1 \pm 1.1 \dagger$ & $26.7 \pm 2.9$ & $24.2 \pm 6.6$ & $29.2 \pm 2.3$ \\
Amniotic fluid & $8.2 \pm 1.4 \dagger$ & $16.5 \pm 2.4 \dagger$ & $23.8 \pm 5.7$ & $23.8 \pm 7.0$ \\
Fetal/maternal & $0.28 \pm 0.04 \ddagger$ & $0.96 \pm 0.02$ & $0.94 \pm 0.09$ & $0.95 \pm 0.04$ \\
blood ratio & & & & \\
\hline
\end{tabular}

* Results are means \pm SE of five to 12 observations/group. At different times after maternal ethanol administration, 21-day pregnant rats were killed. Maternal and fetal blood was collected from the neck after decapitation.

$\dagger$ Value significantly different from the maternal blood, at $P<0.05$.

$\ddagger$ Value different from 1.00 , at $p<0.05$.

Table 1. Blood ethanol $(m M)$ and acetaldehyde $(\mu M)$ concentrations after intragastric ingestion of $4 \mathrm{~g} / \mathrm{kg}$ body wt of ethanol in virgin and pregnant rats*

\begin{tabular}{|c|c|c|c|c|c|c|}
\hline & \multicolumn{6}{|c|}{ Min after ethanol } \\
\hline & 60 & 90 & 120 & 180 & 240 & 300 \\
\hline \multicolumn{7}{|l|}{ Blood ethanol } \\
\hline Virgin & $21.4 \pm 3.1$ & $21.1 \pm 2.6$ & $24.5 \pm 2.3$ & $30.1 \pm 3.1$ & $32.7 \pm 3.7$ & $26.1 \pm 2.4$ \\
\hline 12-day pregnant & $21.3 \pm 3.1$ & $20.5 \pm 3.7$ & $25.3 \pm 6.9$ & $35.2 \pm 7.8$ & & \\
\hline 21-day pregnant & $18.6 \pm 2.6$ & $19.8 \pm 3.5$ & $23.4 \pm 5.1$ & $27.0 \pm 2.9$ & $24.1 \pm 2.3$ & $26.2 \pm 3.4$ \\
\hline \multicolumn{7}{|l|}{ Blood acetaldehyde } \\
\hline Virgin & $32.3 \pm 9.5$ & $33.6 \pm 16.6$ & $19.3 \pm 8.24$ & $18.2 \pm 12.5$ & $1.6 \pm 1.6$ & 0 \\
\hline 12-day pregnant & $58.6 \pm 17.4$ & $24.3 \pm 7.5$ & $17.7 \pm 7.3$ & $37.7 \pm 6.5$ & & \\
\hline 21-day pregnant & $13.9 \pm 4.4$ & $14.5 \pm 7.9$ & $18.4 \pm 7.4$ & $27.5 \pm 12.9$ & $2.3 \pm 2.3$ & $1.2 \pm 1.2$ \\
\hline
\end{tabular}

* Results are means \pm SE of five to nine observations/group. Blood samples were collected from the tail at all times except at 180 and 300 min, which were collected from the neck. Differences between pregnant and virgin rats were insignificant at all times investigated. 
undetectable (Table 3). Acetaldehyde in amniotic fluid was undetectable at all times investigated.

Thus, the fetuses of mothers administered ethanol had very high blood ethanol concentrations, in equilibrium with maternal levels, and undetectable or very low acetaldehyde concentrations. That suggests a very low rate of ethanol oxidation by the fetal/ placental unit. To provide further support for this hypothesis, we investigated the activities of alcohol dehydrogenase in liver from mothers and fetuses and placentas at 17 and 21 days of pregnancy (data are shown in Table 4). At day 17 of pregnancy, alcohol dehydrogenase activities in fetal liver and placenta were undetectable. At 21 days of pregnancy, alcohol dehydrogenase in placenta was still undetectable, although fetal liver attained the significant value of $20 \%$ of adult levels (Table 4). Fetal hepatic alcohol dehydrogenase was undistinguishable from that of the adult liver as judged from their $\mathrm{Km}$ values and from the inhibitory action of pyrazole, a very potent competitive inhibitor of the enzyme (data not shown).

Acetaldehyde metabolism in pregnant rats and their fetuses. In a subsequent series of experiments, $10 \mathrm{mg} / \mathrm{kg}$ body wt of acetaldehyde were injected through the tail vein of virgin and 21-day pregnant rats (Table 5). At $5 \mathrm{~min}$ after acetaldehyde injection, blood concentrations reached maximum and decreased afterward; acetaldehyde concentrations tended to be higher in pregnant rats. However, due to the large standard error, differences were never statistically significant (Table 5). Acetaldehyde concentrations in fetal blood and in amniotic fluid were as high as in maternal blood at all the times considered (Table 5), providing evidence for rapid equilibration in the fetal compartment of acetaldehyde injected in mother.

In Figure 1 individual values of circulating concentrations of acetaldehyde in the mother are plotted against the concentrations in their fetuses after either oral ethanol administration $(\diamond)$ or acetaldehyde injection $(\diamond)$. In experiments with maternal acetaldehyde injection, only pairs of values in which maternal blood concentrations were lower than $250 \mu \mathrm{M}$ were selected. At low acetaldehyde concentrations in maternal blood (lower than 80 $\mu \mathrm{M}$ ), fetal blood acetaldehyde concentrations were below our assay detection limit. However, when blood acetaldehyde concentrations in the mother exceeded $100 \mu \mathrm{M}$, acetaldehyde was

Table 3. Acetaldehyde concentrations ( $\mu M$ ) in maternal and fetal blood and amniotic fluid after maternal administration of $4 \mathrm{~g} / \mathrm{kg}$ body wt of ethanol*

\begin{tabular}{lcccc}
\hline & \multicolumn{4}{c}{ Min after ethanol } \\
\cline { 2 - 5 } & 5 & 15 & 180 & 300 \\
\hline Maternal blood & $33.3 \pm 8.6$ & $42.7 \pm 15.8$ & $45.5 \pm 21.6$ & \\
Fetal blood & ND $\dagger$ & ND & $5.9 \pm 4.0 \ddagger$ & ND \\
Amniotic fluid & ND & ND & ND & ND \\
\hline
\end{tabular}

* Results are means $\pm \mathrm{SE}$ of five to 10 observations/group. At different times after maternal ethanol administration, 21-day pregnant rats were killed. Maternal and fetal blood was collected from the neck after decapitation.

$\dagger$ Not detectable.

$¥$ Value significantly different from maternal blood, at $p<0.05$.

Table 4. Alcohol dehydrogenase activity ( $\mathrm{mU} / \mathrm{mg}$ protein) in maternal and fetal liver and placenta*

\begin{tabular}{lccc}
\hline & Maternal liver & Fetal liver & Placenta \\
\hline Day 17 of pregnancy & $18.6 \pm 1.5$ & ND $\dagger$ & ND \\
Day 21 of pregnancy & $24.1 \pm 3.4$ & $5.3 \pm 1.1 \ddagger$ & ND \\
\hline
\end{tabular}

${ }^{*}$ Results are means \pm SE of seven-eight observations/group. Alcohol dehydrogenase activity was assayed in tissue extracts at $\mathrm{pH} 8.8,25^{\circ} \mathrm{C}$ and $16.7 \mathrm{mM}$ ethanol.

$\dagger$ Not detectable.

$\ddagger$ Significant difference between fetal and maternal values, at $p<0.05$.
Table 5. Acetaldehyde concentrations ( $\mu M$ ) in maternal and fetal blood and amniotic fluid after intravenous administration of $10 \mathrm{mg} / \mathrm{kg}$ body wt of acetaldehyde in virgin and pregnant rats*

\begin{tabular}{lccr}
\hline & \multicolumn{3}{c}{ Min after acetaldehyde } \\
\cline { 2 - 4 } & 2 & 5 & \multicolumn{1}{c}{30} \\
\hline Virgin & $509 \pm 230$ & $947 \pm 387$ & $168 \pm 42$ \\
21-day pregnant & & & \\
$\quad$ Maternal blood & $1303 \pm 455$ & $1355 \pm 391$ & $867 \pm 318$ \\
$\quad$ Fetal blood & $1537 \pm 735$ & $1332 \pm 545$ & $1061 \pm 398$ \\
$\quad \begin{array}{c}\text { Amniotic fluid } \\
\text { Fetal/maternal blood }\end{array} \quad 1722 \pm 720$ & $1913 \pm 675$ & $874 \pm 417$ \\
$\quad$ ratio & $0.98 \pm 0.26$ & $1.01 \pm 0.22$ & $1.02 \pm 0.07$ \\
Amniotic fluid/fetal & $1.23 \pm 0.15$ & $1.06 \pm 0.07$ & $1.24 \pm 0.17$ \\
$\quad$ blood ratio & & & \\
\hline
\end{tabular}

${ }^{*}$ Results are means \pm SE of five to nine observations/group. Acetaldehyde was administered through a tail vein in virgin and 21-day pregnant rats, and maternal and fetal blood was collected from the neck after decapitation at different times. Differences between virgin and 21day pregnant rats were insignificant. Acetaldehyde concentrations in fetal blood and amniotic fluid were never statistically different from maternal blood. In addition, fetal/maternal blood ratio and amniotic fluid/fetal blood ratio were never statistically different from 1.00.

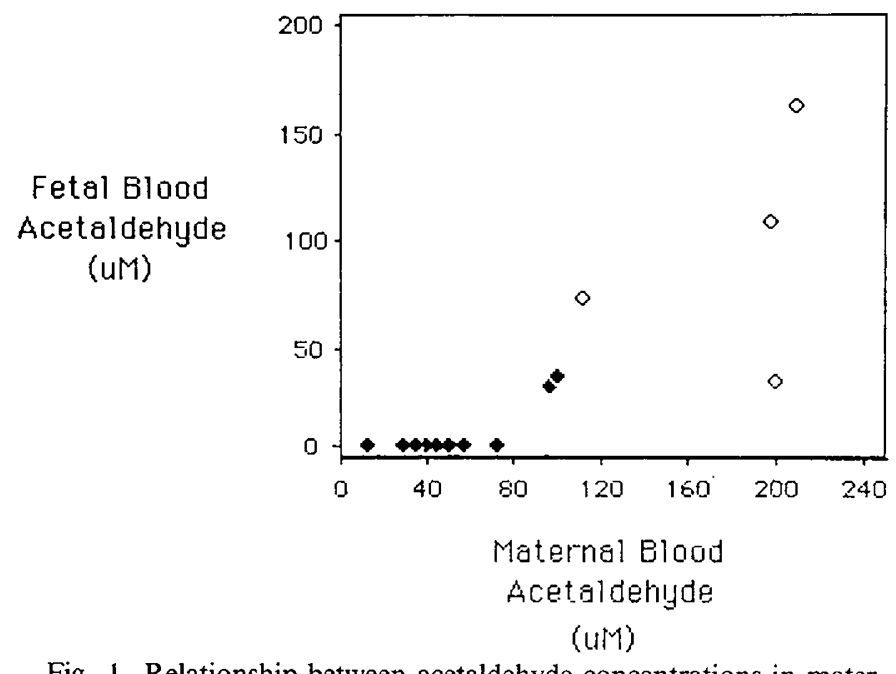

Fig. 1. Relationship between acetaldehyde concentrations in maternal and fetal blood. Plotted values correspond to $180 \mathrm{~min}$ after maternal ethanol administration $(\diamond)$ (Table 3 ) or experiments of maternal acetaldehyde injection $(\diamond)$ (Table 5 ) in which acetaldehyde concentrations in mother were lower than $250 \mu \mathrm{M}$

evident in fetal blood (Fig. 1). These data are consistent with the existence of a barrier against acetaldehyde, perhaps constituted by the placenta and fetal liver, that is efficient at low acetaldehyde levels but that can be surpassed under our experimental conditions at acetaldehyde concentrations more than $80 \mu \mathrm{M}$.

We next examined the activities of aldehyde dehydrogenase in maternal and fetal liver and placenta at different days of pregnancy (Table 6). In both placenta and fetal liver, aldehyde dehydrogenase activity was present at 17 or 21 days of pregnancy when assayed at $0.05,0.3$, or $20 \mathrm{mM}$ acetaldehyde. Aldehyde dehydrogenase activities in fetal liver were lower than in liver from the adult rat, and higher than in the placenta (Table 6). In 21-day pregnant rats versus the 17-day rats, the activity of the high $\mathrm{Km}$ aldehyde dehydrogenase isoenzyme increased in fetal liver; by contrast, placental aldehyde dehydrogenase, if anything, tended to decrease at late pregnancy (Table 6). Kinetic characterization of the high $\mathrm{Km}$ isoenzymes of aldehyde dehydrogenase from adult and fetal liver and placenta in the 21-day pregnant 
Table 6. Aldehyde dehydrogenase activity ( $\mathrm{mU} / \mathrm{mg}$ protein) in maternal and fetal liver and placenta*

\begin{tabular}{cccc}
\hline & Maternal liver & Fetal liver & Placenta \\
\hline $\begin{array}{c}\text { Day } 17 \text { of pregnancy } \\
0.05 \mathrm{mM} \text { acetalde- } \\
\text { hyde }\end{array}$ & $1.39 \pm 0.23$ & $0.57 \pm 0.29 \dagger$ & $0.15 \pm 0.03 \dagger$ \\
$0.30 \mathrm{mM}$ acetalde- \\
hyde & $2.67 \pm 0.30$ & $0.89 \pm 0.34 \dagger$ & $0.15 \pm 0.09 \dagger \ddagger$ \\
$\begin{array}{c}20 \mathrm{mM} \text { acetalde- } \\
\text { hyde }\end{array}$ & $27.99 \pm 0.46$ & $2.87 \pm 0.57 \dagger$ & $0.50 \pm 0.09 \dagger \ddagger$ \\
$\begin{array}{c}\text { Day } 21 \text { of pregnancy } \\
0.05 \mathrm{mM} \text { acetalde- } \\
\text { hyde }\end{array}$ & $1.25 \pm 0.23$ & $0.73 \pm 0.37$ & $0.07 \pm 0.02 \dagger \ddagger$ \\
$0.30 \mathrm{mM}$ acetalde- \\
hyde
\end{tabular}

* Results are means $\pm \mathrm{SE}$ of six to eight observations/group. Aldehyde dehydrogenase activity was assayed in liver and placental extracts at $\mathrm{pH}$ $8.8,37^{\circ} \mathrm{C}$ and $0.05 \mathrm{mM}, 0.30 \mathrm{mM}$ or $20 \mathrm{mM}$ acetaldehyde to differentiate between high and low affinity components.

$\dagger$ Significant difference from maternal liver activity, at $p<0.05$.

$\ddagger$ Significant difference between fetal and placental activities, at $p<$ 0.05 .

$\S$ Significant difference between 17-day and 21-day pregnant groups, at $p<0.05$.

Table 7. Kinetic parameters of low affinity aldehyde dehydrogenase in maternal and fetal liver and placenta in the 21-day pregnant rat*

\begin{tabular}{lcc}
\hline & $\begin{array}{c}\mathrm{Km} \text { acetaldehyde } \\
(\mathrm{mM})\end{array}$ & $\begin{array}{c}\mathrm{V}_{\max } \\
(\mathrm{U} / \mathrm{g} \text { tissue })\end{array}$ \\
\hline Maternal liver & $6.8 \pm 0.8$ & $3.3 \pm 0.5$ \\
Fetal liver & $7.6 \pm 1.1$ & $0.5 \pm 0.04 \dagger$ \\
Placenta & $5.5 \pm 1.1$ & $0.03 \pm 0.004 \ddagger$ \\
\hline
\end{tabular}

* Results are means \pm SE of five to seven observations/group. Aldehyde dehydrogenase activity was assayed in liver and placental extracts at $\mathrm{pH} 8.8,37^{\circ} \mathrm{C}$ and different concentrations of acetaldehyde.

$\dagger$ Significant difference from maternal liver activity, at $p<0.05$.

$\ddagger$ Significant difference between fetal and placental activities, at $p<$ 0.05 .

rat, indicated that the enzymes isolated from all the tissues studied had similar $\mathrm{Km}$ values, and differences between them were a consequence of changes at the $V_{\max }$ level (Table 7). Additional support for the existence of a normal form of aldehyde dehydrogenase in fetal liver and in placenta was the fact that sensitivity to disulfiram inhibition was similar in aldehyde dehydrogenase from adult liver, placenta or fetal liver tissues (data not shown).

\section{DISCUSSION}

Under our experimental conditions, the rate of ethanol metabolism after oral administration did not differ between control and pregnant rats. We did not observe differences in the pattern of acetaldehyde appearance after oral ethanol administration between pregnant and nonpregnant rats, contrary to previous observations $(15,24)$. Whether this was due to differences in the nutritional status of the animals or to the ethanol dose administered remains to be seen. However, we found that the metabolism of acetaldehyde after intravenous administration was somewhat retarded in the pregnant animals, in keeping with previous observations $(15,26)$. It is possible that the oral dose of ethanol used in this study $(4 \mathrm{~g} / \mathrm{kg})$ exceeded the maternal ability to metabolize this compound. However, this possibility is unlikely because, under conditions similar to those used here, it was previously found in the rat that both plasma ethanol and acetaldehyde concentrations increased proportionally to the ethanol dose, ranging from $1-4 \mathrm{~g} / \mathrm{kg}$ of body wt (10), suggesting that the highest dose was not yet sufficient to reach the maximal rate of overall ethanol metabolization.

Ethanol rapidly crosses the placenta after maternal administration. This is a consequence of the rapid passage of ethanol through membrane structures and the fact that no alcohol dehydrogenase activity is present in the rat placenta (27). This explains the rapid equilibration in the maternal and fetal compartments after maternal ethanol administration. In addition, although fetal liver alcohol dehydrogenase is absent at day 17 of pregnancy, in the 21-day pregnant rat, fetal alcohol dehydrogenase is very low, and when observed values are used to calculate liver capacity for ethanol oxidation, it appears to be approximately $0.12 \mu \mathrm{mol} / \mathrm{min} /$ fetal liver, which represents $20 \%$ of adult liver activity. This ethanol oxidation capacity is in agreement with other reports in rats and in humans $(27-30)$, and it is very low compared to the initial net input of ethanol from mother to fetus, estimated at approximately $8 \mu \mathrm{mol} / \mathrm{min}$ (from data in Table 2). Thus, maximal fetal liver capacity is less than $2 \%$ of the total ethanol received by the fetus. However, the fetal hepatic alcohol dehydrogenase appeared similar to the adult form on the basis of kinetic and inhibition studies; previous observations in fetal human liver had suggested a fetal isozyme of alcohol dehydrogenase that was different from the adult form (31).

One question worth posing is whether ethanol is effectively metabolized by fetal liver alcohol dehydrogenase in vivo. This question is relevant in the light of data obtained with perfused livers from 10- to 16-wk-old human fetuses which, despite detectable alcohol dehydrogenase activity (10\% of adult levels) (30), did not metabolize $1 \mathrm{mM}$ ethanol (32). In any case, unless the presence of an enzyme inhibitor or an enhancement in the shunting of umbilical venous flow via the ductus venosus secondary to other pharmacologic effects of ethanol or acetaldehyde are postulated at the saturating ethanol concentrations observed in our experiments (close to $30 \mathrm{mM}$ ), alcohol dehydrogenase from fetal liver is likely to oxidize ethanol, although at a low rate. Assuming bidirectional ethanol flux, we propose that ethanol metabolism in the fetoplacental unit is carried out mainly by the maternal liver rather than by fetal tissues.

Our results indicate that acetaldehyde, when present at high concentrations in maternal blood, freely crosses the placenta, because 2 min after maternal intravenous administration, acetaldehyde in maternal blood reaches equilibrium with the fetal blood and amniotic fluid compartments. Acetaldehyde is a small liposoluble molecule and is able to cross membranes by simple diffusion. In spite of this, we did not observe acetaldehyde in fetal peripheral blood in ethanol administration experiments with pregnant rats. Only when maternal acetaldehyde concentrations were higher than $80 \mu \mathrm{M}$ was acetaldehyde detected in fetal blood. Lower maternal acetaldehyde levels that reach fetal tissues or the placenta seem to be metabolized by these structures. At late gestation, both placenta and fetal liver have been found to contain aldehyde dehydrogenase activity $(27,29,33-35)$, and the activities found in the present study correspond to $25 \%$ and $1.5 \%$ of adult levels in fetal liver and placenta, respectively (Table $6)$.

On the basis of the low acetaldehyde levels present in blood even after high ethanol intake, we propose that both fetal liver and placenta oxidize most of the acetaldehyde made available to them from the maternal circulation. This proposal is supported by the findings that only $25 \%$ of the acetaldehyde content of maternal aortic blood could be found in the rat placenta, and no acetaldehyde was detected in fetal tissues (16). Placental blood flow in the rat is approximately $0.9 \mathrm{ml} / \mathrm{min} /$ placenta (36). Assuming an average circulating concentration of acetaldehyde of $30 \mathrm{nmol} / \mathrm{ml}$ (see Table 2) and a percentage extraction of $30 \%$, similar to a very diffusible molecule such as oxygen (37), there should be an entry of approximately $9 \mathrm{nmol}$ of acetaldehyde/ 
$\mathrm{min} /$ placenta. Although the placenta would not be capable of eliminating all the acetaldehyde coming from the mother, at low acetaldehyde concentrations, the combined capacity for acetaldehyde oxidation of the fetal liver and placenta is approximately $20 \mathrm{nmol} / \mathrm{min}$; therefore, acetaldehyde would be totally removed from fetal blood. At higher maternal acetaldehyde concentrations (for instance, at $100 \mu \mathrm{M}$ ), the entry of acetaldehyde in one single placenta could be as high as $30 \mathrm{nmol} / \mathrm{min}$, an influx that might surpass the acetaldehyde removal capacity of the fetoplacental unit. Our data are consistent with the idea of an acetaldehyde threshold above which the capacity of acetaldehyde metabolism by the fetoplacental unit could be surpassed. In the present study we found that this acetaldehyde threshold might be close to 80 $\mu \mathrm{M}$ (maternal blood concentration) in the 21-day pregnant rat. It is very likely that the threshold concentration is much lower at early pregnancy when aldehyde dehydrogenase is absent from fetal liver.

In summary, the results of the present study demonstrate that at late pregnancy ethanol crosses the placenta very rapidly after maternal administration, reaching equilibrium 15 min after its administration. Equilibration of ethanol between fetal blood and amniotic fluid is even faster, being observed 5 min after ethanol administration. Thus, the elimination of ethanol in the fetus is mainly carried out by the maternal liver. Furthermore, acetaldehyde at high concentrations is able to cross the placental barrier very rapidly; at low maternal concentrations (lower than $80 \mu \mathrm{M}$ ), it is metabolized by aldehyde dehydrogenase activity in placenta and fetal liver, and acetaldehyde is not detected in fetal blood; above an acetaldehyde threshold, the capacity of acetaldehyde metabolism by the fetoplacental unit is surpassed and acetaldehyde is detected in fetal blood.

Acknowledgments. The authors thank M. Morante for excellent technical work and Carol F. Warren from the ICE of Alcalá de Henares for the editorial help.

\section{REFERENCES}

1. Chernoff GF 1977 The fetal alcohol syndrome in mice: an animal model. Teratology 15:223-230

2. Randall CL, Taylor WJ, Walker DW 1977 Ethanol-induced malformations in mice. Alcoholism Clin Exp Res 1:219-224

3. Schwetz BA, Smith FA, Staples RE 1978 Teratogenic potential of ethanol in mice, rats and rabbits. Teratology 18:385-392

4. Jones KL, Smith DW, Ulleland CN, Streissguth AP 1973 Pattern of malformation in offspring of chronic alcoholic mothers. Lancet 1:1267-1271

5. Jones KL, Smith DW 1973 Recognition of the fetal alcohol syndrome in early infancy. Lancet 2:999-1001

6. Jones KL, Smith DW, Streissguth AP, Myrianthopoulos NC 1974 Outcome in offspring of chronic alcoholic women. Lancet 1:1076-1078

7. Hanson JW, Jones KL, Smith DW 1976 Fetal alcohol syndrome: experience with 41 patients. JAMA 235:1458-1460

8. Henderson GI, Patwardhan RV, Hoyumpa AM Jr, Schenker S 1981 Fetal alcohol syndrome: overview of pathogenesis. Neurobehav Toxicol Teratol

9. Rawat AK 1976 Effect of maternal ethanol consumption on fetal hepatic metabolism in the rat. Ann NY Acad Sci 273:175-18

10. Abel EL 1982 Consumption of ethanol during pregnancy: a review of effects on growth and development of offspring. Hum Biol 54:421-453
11. Testar X, Llobera M, Herrera E 1988 Comparative metabolic effects of chronic ethanol intake and undernutrition in pregnant rats and their fetuses. Alcoholism Clin Exp Res 12:197-200

12. Dilts PV 1970 Placental transfer of ethanol. Am J Obstet Gynecol 107:11951198

13. Kaufman M, Woollam DHM 1981 The passage to the foetus and liquor amnii of ethanol administered orally to the pregnant mouse. Br J Exp Pathol $62: 357-361$

14. Brien JF, Clarke DW, Richardson B, Patrick J 1985 Disposition of ethanol in maternal blood, fetal blood and amniotic fluid of third-trimester pregnant ewes. Am J Obstet Gynecol 152:583-590

15. Gordon BHJ, Baraona E, Miyakawa H, Finkelman MS, Lieber CS 1985 Exaggerated acetaldehyde response after ethanol administration during pregnancy and lactation in rats. Alcoholism Clin Exp Res 9:17-22.

16. Kesaniemi YA, Sippel HW 1975 Placental and foetal metabolism of acetaldehyde in rat: I: contents of ethanol and acetaldehyde in placenta and foetus of the pregnant rat during ethanol oxidation. Acta Pharmacol Toxicol 37:43-

17. O'Shea KS, Kaufman MH 1979 The teratogenic effect of acetaldehyde: implications for the study of the fetal alcohol syndrome. J Anat 128:65-76

18. Mena MA, Zorzano A, Herrera E 1986 Acute effects of ethanol on brain, plasma and adrenal monoamine concentrations in virgin and pregnant rats and their fetuses. Neurochem Int 9:371-378

19. Guerri C, Sanchís R 1985 Acetaldehyde and alcohol levels in pregnant rats and their fetuses. Alcohol 2:267-270

20. Von Wartburg JP, Riss MM 1979 Determination of acetaldehyde in human blood. Experientia 35:1682-1683

21. Zorzano A, Ruiz del Arbol L, Herrera E 1988 Effect of liver disorders on ethanol elimination and alcohol and aldehyde dehydrogenase activities in liver and erythrocytes. Clin Sci 75:(in press)

22. Von Wartburg JP, Papenberg J, Aebi H 1965 An atypical human alcohol dehydrogenase. Can J Biochem 43:889-898

23. Blair AH, Bodley FH 1969 Human liver aldehyde dehydrogenase: partial purification and properties. Can J Biochem 47:265-275

24. Herrera E, Zorzano A, Fresneda V 1983 Comparative kinetics of human and rat liver alcohol dehydrogenase. Biochem Soc Trans 11:729-730

25. Lowry OH, Rosebrough NJ, Farr AL, Randall RJ 1951 Protein measurement with the folin phenol reagent. J Biol Chem 193:265-275

26. Kesaniemi YA 1974 Metabolism of ethanol and acetaldehyde in intact rats during pregnancy. Biochem Pharmacol 23:1157-1162

27. Sjoblom M, Pilstrom L, Morland J 1978 Activity of alcohol dehydrogenase and acetaldehyde dehydrogenases in the liver and placenta during the development of the rat. Enzyme 23:108-115

28. Raiha NCR, Koskinen M, Pikkarainen P 1967 Developmental changes in alcohol-dehydrogenase activity in rat and guinea-pig liver. Biochem $\mathrm{J}$ 103:623-626

29. Horton AA, Mills DJ 1979 Developmental patterns of alcohol dehydrogenase and aldehyde dehydrogenases in homogenates and subcellular fractions of rat liver. Mech Ageing Dev 11:363-370

30. Pikkarainen PH, Raiha NCR 1967 Development of alcohol dehydrogenase activity in the human liver. Pediatr Res $1: 165-168$

31. Pikkarainen P, Raiha NCR 1969 Change in alcohol dehydrogenase isoenzyme pattern during development of human liver. Nature 222:563-564

32. Pikkarainen PH 1971 Metabolism of ethanol and acetaldehyde in perfused human fetal liver. Life Sci 10:1359-1364

33. Kouri M, Koivula T, Koivusalo M 1977 Aldehyde dehydrogenase activity in human placenta. Acta Pharmacol Toxicol 40:460-464

34. Sippel HW, Kesaniemi YA 1975 Placental and foetal metabolism of acetaldehyde in rat: II: studies on metabolism of acetaldehyde in the isolated placenta and foetus. Acta Pharmacol Toxicol 37:49-55

35. Pikkarainen PH 1971 Aldehyde-oxidizing capacity during development in human and rat liver. Ann Med Exp Biol Fenniae 49:151-156

36. Palacín M, Lasunción MA, Herrera E 1985 Decreased uterine blood flow in the diabetic pregnant rat does not modify the augmented glucose transfer to the fetus. Biol Neonate 48:197-203

37. Meschia G 1978 Substrate availability and fetal growth. In: Naftolin, Abnormal Fetal Growth: Biological Basis and Consequences. Dahlem Konferences, Life Sciences Research Report 10, Berlin, pp 221-228 